\title{
Benzoic Acid Residue in Nepalese Fruits and Vegetable Products
}

\author{
KRISHNA PRASAD RAI*, SOVITA SHRESTHA, JIWAN PRAVA LAMAand BINAYA PRASAD SHRESTHA
}

\author{
Department of Food Technology and Quality Control, Kathmandu, Nepal
}

The research was carried out first time in Nepal to study the residue level of benzoic acid in fruits and vegetable products by HPLC method. Altogether, 40 different samples of pickles, tomato ketchups, jam and some fresh condiments were analyzed. The maximum concentration of benzoic acid $(2192.4 \mathrm{mg} / \mathrm{kg})$ was found in pickles made in household level, while minimum quantity $(10.29 \mathrm{mg} / \mathrm{kg})$ was found in jam product. Altogether, $19.35 \%$ of samples analyzed were found to be contaminated with higher quantity of benzoic acid as comparing to mandatory standard of Nepal. Individually, 33.33\%, 10.00\% and 11.11\% of samples were found to be substandard for pickles, tomato ketchups and jam respectively. Apparently, pickle samples were found to have higher amount of benzoic acid as compare to others and no any evidence for natural contamination of benzoic acid in vegetable products was observed. Furthermore, a simple water extraction method for sample preparation and new HPLC procedure was established as a routine method for benzoic acid analysis.

Keywords: Benzoic acid, HPLC, Water extraction, Fruits and vegetable products

\section{Introduction}

Benzoic acid (E210; benzene carboxylic acid; C7H6O2) and its sodium (E211), potassium (E212) and calcium (E213) salts (further referred to as "benzoates") are a group of food additives important to preserve foods and to protect the consumer from microbiological risks of various bacteria, yeasts and fungi that can be involved in food poisoning, such as Escherichia coli, Listeria monocytogenes, Aspergillus spp. and Penicillium spp. (Sieber et al., 1995). They are also used in other products except foods such as pharmaceuticals and cosmetics. It has been estimated that about 638,000 tons of benzoic acid has been produced globally per year (WHO, 2000).

Due to its weak solubility in water $(0.34 \mathrm{~g} / 100 \mathrm{~g})$, its sodium salt i.e. sodium benzoate $(63 \mathrm{~g} / 100 \mathrm{~g})$ is popularly used in fruits and vegetable preservation (Kharel and Hasinaga, 2004). It has a bacteriostatic and fungistatic effect under acidic conditions $\mathrm{pH}$ below 4.0. Therefore, it is used most prevalently in acidic foods such as salad dressings, carbonated drinks, jams and fruit juices, pickles and other condiments. In Nepal, the use of benzoic acid in different fruits and vegetable products such as alcoholic and non alcoholic beverages, jam, jelly, marmalade, pickles, preserve, fruit juice, tomato sauce, ketchup and puree etc. has been limited by Food Regulation1971 (Rai, 2010). Therefore, the quantitative determination thereof is warranted for routine analysis of these types of product.

However a low quantity of benzoic acid has been detected in some natural fruits and vegetables viz. cranberries, prunes, greengage plums, cinnamon, ripe cloves and apples. A quite significant level of benzoic acid has been detected in raw milk in china (Qi et al., 2009). Similarly, different brands of soft drink, fruit juice, margarine, yoghurt and cheese products were found to be added a significant amount of benzoic acid in Brazilian market (Tfouni et al., 2002).

JECFA (WHO, 1996) has evaluated and established an acceptable daily intake (ADI) for benzoic acid, benzoate salt (calcium, potassium and sodium), benzaldehyde, benzyl acetate and benzyl alcohol of $0-5 \mathrm{mg} / \mathrm{kg}$ body weight. In generally recognized as safe to a maximum level of use of benzoic acid is $0.1 \%$ in the US and up to $0.25 \%$ in some other developing countries. Because of varying diets among countries, the foods that mainly contribute to the intake of benzoic acid and its salt are expected to vary. Because of its ability to cause contact urticaria it can provoke itching and tingling in the mouth in sensitive subjects (Clemmensen and Hjort, 1982). Some toxicological study claimed that benzoic acid can damage and inactivate vital parts of DNA in a cell's mitochondria leading the disease like Parkinson's and other neurodegenerative diseases (Anonymous, 2010a).

Its toxicological data shows $\mathrm{LD}_{50}$ orally for mouse and rat as $1940 \mathrm{mg} / \mathrm{kg}$ and $1700 \mathrm{mg} / \mathrm{kg}$ respectively (RTC, 2010).

There are several quantitative determination techniques for benzoic acid in food products viz. simple chloroform extraction and gravimetric method, HPLC method, GC methods etc. (Lino and Pena 2010; Qi et al., 2009; Tfouni and Toledo 2002; Ferreira et al., 2000). Reviewing all the methods of analysis, this study aimed to establish a new and cost effective water extraction procedure for sample preparation and establish a specific HPLC procedure for analyzing benzoic acid residue in fruits and vegetable products available in Nepalese markets.

*Corresponding author, E-mail: krishnamalarai@yahoo.com 


\section{Materials and Methods}

Sampling: A purposive sampling technique was carried out to collect randomly altogether 40 different fruits and vegetable products available in Nepalese markets such as Hetauda, Chitwan, Sunsari, Kathmandu, Kavere, Pokhara and Dhading etc. All samples were packed in either glass jars or plastic pouches and kept in refrigeration until the final analysis was done.

Certified Reference Material (CRM) of benzoic acid was purchased from RT Pharma, UK and an ISO Guide 34:2000 Reference material producer company.

Sample extraction and preparation: The samples were extracted in water according to the following method (Figure 1.)

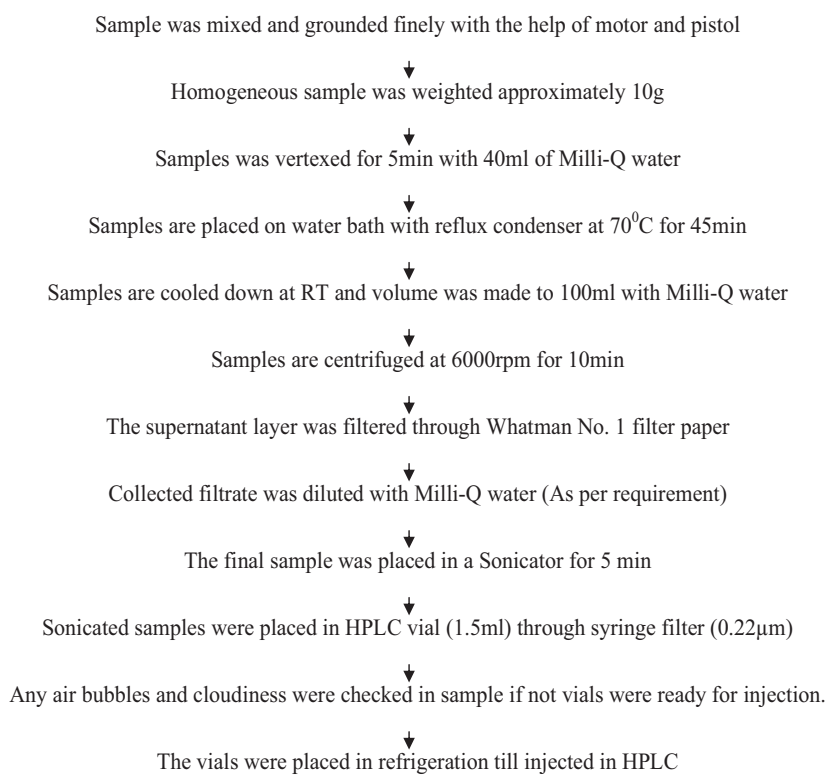

Figure 1. Water extraction method of sample preparation for benzoic acid

Preparation of CRM standard: Firstly, 1000ppm of benzoic acid stock solution was prepared in Milli-Q water (Milli-Q, Academic, A10). A freshly 1, 2.5, 5 and 10 ppm of external standards were prepared by dilution of stock sample with
Milli-Q water. The standards were vertexed well and kept for $5 \mathrm{~min}$ in sonicator (PCI, India, 3.5L-100) before place in HPLC vials through syringe micro filter (Milli-Q, $0.22 \mu \mathrm{m}$ ). The standard curve for concentration against peak area was plotted and the coefficient of determinants $\left(\mathrm{R}^{2}=0.9991\right)$ was obtained with equation $y=43816 x$, where the value ' $x$ ' is the concentration of benzoic acid in sample.

Determination of Benzoic acid by HPLC: All the analysis was carried out by using HPLC from Shimadzu equipped with prominent degasser (DGU-20As), double pumps (LC-20AD), Auto sampler (SIL-20A), detector, UV/VIS (SPD-20A), column oven (CTO-20A) and LC solution software. The column used was Pursuit C18 (Varian, 4.6x250. 10 $\mu \mathrm{m}$ ). The gradient mobile phase consisted of 70:30 (0.02M phosphate buffer, $\mathrm{pH} 7.0$ : Methanol) with the flow rate $0.8 \mathrm{ml} / \mathrm{min}$ at $40^{\circ} \mathrm{C}$. The injection volume was $10 \mu 1$. The peak of benzoic acid was measured at $230 \mathrm{~nm}$. Chromatographic peaks were identified by comparing retention time and spectra with the aqueous solution of the standard. Quantification was based on the external standard method and the concentrations of benzoic acid were 1.0, 2.5, 5.0 , and $10.0 \mathrm{ppm}$. The best fit standard curve was prepared by linear regression of peak areas versus concentration. The determination of limit (LOD) was calculated, corresponding to the analyte concentration equivalent to the blank signal plus three standard deviations of the blank. The LOD for benzoic acid was, respectively, $0.5 \mathrm{mg} / \mathrm{kg}$ in all products. The analysis was conducted in duplicate.

Statistical analysis: The data obtained from analysis were statistically analyzed by using the Microsoft Office Excel 2003.

\section{Results and Discussion}

Recovery: In order to verify the accuracy and precision of analytical procedure, process recovery studies were carried out. The known amount of benzoic acid (3 levels) was added to the samples of ketchup and pickle. The mean recoveries for ketchup and pickles were $100.40 \%$ and $99.68 \%$ respectively. Spiked samples were analyzed in triplicates. Tfouni and Toledo (2002) have found a similar result of recovery for pineapple fruit juice as $98.7 \%$ and for coca soft drink as $102.2 \%$.

Table 1. Recovery of benzoic acid from tomato ketchup and pickle

\begin{tabular}{|c|c|c|c|}
\hline Sample & Spiked amount (mg/kg) & Recovery (\%) & $\begin{array}{c}\text { Mean recovery } \pm \mathrm{SD} \\
(\%)\end{array}$ \\
\hline \multirow[t]{3}{*}{ Tomato ketchup } & 20 & 101.3 & $100.4 \pm 2.66$ \\
\hline & 30 & 97.41 & \\
\hline & 40 & 102.51 & \\
\hline \multirow[t]{3}{*}{ Pickle } & 20 & 102.87 & $99.68 \pm 2.13$ \\
\hline & 30 & 98.56 & \\
\hline & 40 & 97.61 & \\
\hline
\end{tabular}


Benzoic acid results: Altogether, 40 numbers of different fruits and vegetable samples were analyzed and the result of benzoic acid content is presented in Table 2 , and a typical chromatogram of benzoic acid in sample is shown in Figure 2. According to mandatory standard of Government of Nepal, the maximum permitted level of benzoic acid in pickle, ketchup and sauce and jam products shall be not more than 250,750 and $200 \mathrm{mg} / \mathrm{kg}$ respectively (Food Regulation, 1970). The result showed that out of 31 samples (pickles, ketchups and jam) only $6(19.35 \%)$ were found to be contaminated with exceed amount of benzoic acid (Food Regulation, 1970). Individually, pickle, ketchup and jam contributed to substandard as 33.3, 10.0 and $11.11 \%$ respectively (Figure 3 ).

Apparently, the result showed that the pickle samples were found to be added exceeded amount of benzoic acid as compare to other food samples. However, the products from some renowned brands of Nepal were found to be within standard. Mostly, the pickle samples collected from cottage industry or even at home scales were found to be substandard. This could be due to the lacking of proper knowledge, accurate weighing balance and awareness on health hazard of such food additives.

In Taipei of Taiwan, a city health survey conducted in 2010 also revealed that $30 \%$ of tested dried and pickled foods failed a test having too much benzoic acid, which is known to affects on liver and kidney function (Anonymous 2010b). Similarly, a recent research conducted in China also showed that the benzoic acid was detected in $76.8 \%$ of milk sample quantity ranging from $0.51-111.0 \mathrm{mg} / \mathrm{kg}(\mathrm{Qi}$, et al., 2009).

Moreover, other 9 samples of fresh green and red chilies, dry chili powder and ginger did not show the presence of benzoic acid naturally. No peak of benzoic acid was found in chili powder (Figure 4). This result concluded that any forms of chilies or ginger were not contributing factor for benzoic acid in such fruits and vegetable products. It also proved that no evidence of benzoic acid present in such single spices, which were doubted to have contribution of benzoic acid in Nepalese fruits and vegetable products such as pickles, tomato ketchups etc.

Table 2. Analysis result of Benzoic acid in different fruits and vegetable products

\begin{tabular}{|c|c|c|c|c|c|c|}
\hline Category* & $\mathbf{N}_{\mathbf{A}}$ & $\mathbf{N}_{\mathbf{D}}$ & Minimum & Maximum & Mean & SD \\
\hline Pickles & 12 & $5(41.67 \%)$ & 0 & 2192.4 & 245.55 & 594.13 \\
\hline Tomato ketchups & 10 & 0 & 134.58 & 984.60 & 433.17 & 226.70 \\
\hline Jam & 9 & 0 & 10.29 & 251.54 & 97.26 & 74.77 \\
\hline $\begin{array}{l}\text { Miscellaneous } \\
\text { and Ginger) }\end{array}$ & 9 & $9(100 \%)$ & ND & ND & ND & ND \\
\hline
\end{tabular}

*The quantity is in $\mathrm{mg} / \mathrm{kg}$

$\mathrm{Nd}=$ Not detected in sample

$\mathrm{ND}=$ Not detected chromatographic peak

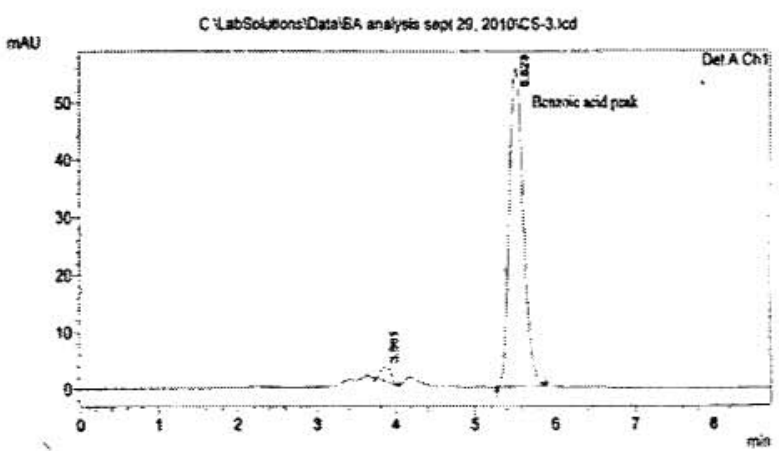

Figure 2. Chromatogram of benzoic acid in Chili sauce

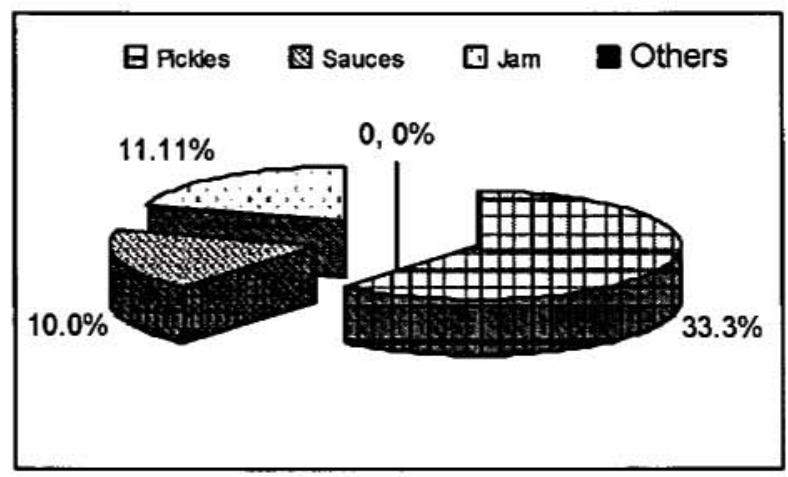

Figure 3. Percentage of substandard food samples 


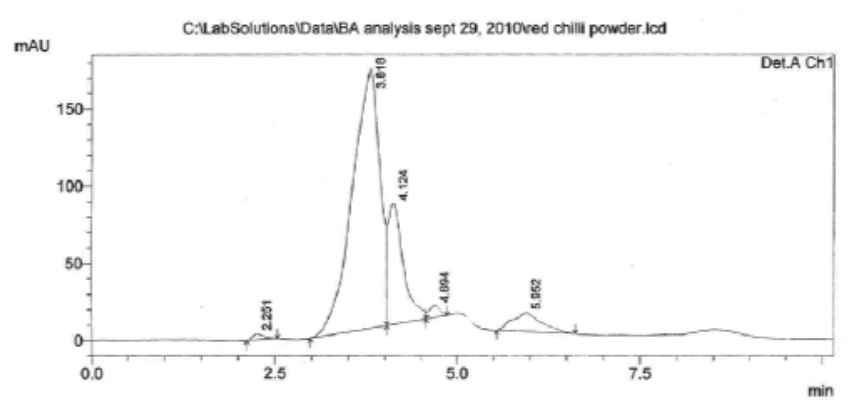

Figure 4. Chromatogram of Chili powder

\section{Conclusion}

The study result revealed that $19.35 \%$ of fruits and vegetable products were found to be contaminated with exceeding quantity of Nepal government's standard. Individually, 33.33, 10.00 and $11.11 \%$ of samples were found to be substandard for pickles, ketchups and jam respectively. The maximum residue level of benzoic acid $(2,192.4 \mathrm{mg} / \mathrm{kg})$ was found in pickles made in household level, while minimum quantity $(10.29 \mathrm{mg} / \mathrm{kg})$ was found in reputed brand for jam product. Apparently, pickle samples were found to have higher amount of benzoic acid as compare to others, which might be due to the ignorance and lacking of facility for quality control (unpublished survey data) in such household level industries. Similarly, no any evidence for natural contamination of benzoic acid in vegetable products was observed. Furthermore, a simple and reliable water extraction method for sample preparation and new HPLC procedure was established for routine method for benzoic acid analysis.

\section{Acknowledgements}

This study was conducted according to the annual research program entitled as 'Study on benzoic acid residue in fruits and vegetables products' of DFTQC, Central Food Laboratory in 2010. The first author is grateful to Mr. Ramesh Sthapit, former DDG of DFTQC for giving me this opportunity and also thankful to Ms. Helen Shrestha and Dipendra Ghimire for sample collection and all the other staffs of CFL, who directly and indirectly supports to complete this work.

\section{References}

Anonymous (2010a). Sodium Benzoate. Available in website: http://en.wikipedia.org/wiki/

Anonymous (2010b). TAIWAN: Nearly 30\% dried, pickled foods fail safety inspections, China post. Available at http://bites.ksu.edu/news/139125/10/01/19/taiwannearly-30-dried-pickled-foods-fail-safety-inspections.

Clemmensen O. and Hjort N. (1982). Perioral contact urticaria from sorbic acid and benzoic acid I a salad dressing, Contact Dermatitis, 8:1-6.
Ferreira I. M. P. L. V. O., Mendes E. M., Brito P. and Ferreira M. A. (2000). Simultaneous determination of benzoic and sorbic acids in quince jam by HPLC. Food Research Int., 33: 113-117.

JECFA(WHO, 1996). Toxicological evaluation of certain food additives. WHO Food Additives Series, 37. Available in website: http://www.inchem.org/documents/jecfa/ jecmono/v37je05.htm

Food Regulation (1970). Food Regulation, Government of Nepal.

Kharel and Hasinaga (2004). Food Preservation by Preservatives, In: Principle of Food Preservation. Shibundo Co. Ltd, Japan, pp 178-198.

Lino C. M. and Pena A. (2010). Occurrence of caffeine, saccharin, benzoic acid and sorbic acid in soft drinks and nectars in Portugal and subsequent exposure assessment. Food Chem., 121: 503-508.

Qi P., Hong H. Liang X. and Liu D. (2009). Assessment of benzoic acid levels in milk in China. Food Control, 20: 414-418.

Rai K. P. (2010). Post harvest technology of fruits and vegetable processing (in Nepali). Inclusive Consultants Pvt. Ltd, Kathmandu, Nepal.

RTC (2010). MSDS for Benzoic acid, RTC, UK.

Sieber R., Butikofer U. and Bosset J. O. (1995). Benzoic acid as a natural compound in cultured dairy products and cheese. Int. Dairy J. 5: 227-246.

Tfouni S. A. V and Toledo M. C. F. (2002). Determination of benzoic and sorbic acids in Brazilian food. Food Control., 13: $117-123$.

WHO (1996). Toxicological evaluation of certain food additives. WHO Food Additives Series, 37. Available in website: http://www.who.int/ipcs/publications/jecfa/ monographs/en/. 2010.

WHO (1997). Evaluation of some food additives and contaminants. Technical Report Series, 868. Available in website: http://www.who.int/ipcs/publications/jecfa/ reports/en/index.html, 2010.

WHO (2000). Benzoic acid and sodium benzoate. Concise international chemical assessment document, 26. Available in website: http://www.inchem.org/documents/ cicads/cicads /cicad26.htm, 2010. 